\title{
The effect of training on consumption time and preference
}

\author{
GEORGE WOLFORD and TERRI S. LUSTICK \\ Dartmouth College, Hanover, New Hampshire
}

\begin{abstract}
Two experiments were carried out to examine the influence and limits of training on rats' preference. In the first experiment, rats' preference for barpress food versus freely available food was alternated between the two choices via interspersed training. The second experiment demonstrated that the preference could not be alternated indefinitely but eventually remained constant, with a strong free-food preference. Consumption rates during training sessions with barpressing and with free food showed that the number of pellets an animal consumed per minute increased with training. Both choice alternatives yielded similar learning curves. Free food demonstrated a slight initial advantage over and reached a higher asymptote than did the barpress. Preference during training could be predicted on the basis of which alternative was more efficient at that time.
\end{abstract}

Since Jensen's (1963) initial experiment, a number of experimenters have documented and explored the "contrafreeloading" or "free food" phenomenon. Jensen found that when rats were given a choice between barpressing for food or eating it directly from a bowl of freely available food, the percentage of food obtained via the barpress increased monotonically with increases in the amount of barpress training prior to the test. Much of the research since 1963 has been directed toward examining the variables that affect whether animals prefer to barpress for food or eat "response-independent and continuously available food," often referred to as free food (Osborne, 1977, p. 222).

A range of training procedures has been utilized in preparation for the choice situation. Some evidence indicating that training procedures may contribute to the animal's preference has emerged. One such procedure was utilized by Carder and Berkowitz (1970), who gave rats 3 days of free-food training and then 6 days of barpress training. Each choice day began with 25 earned food pellets prior to the insertion of free food into the Skinner box. This procedure resulted in an overwhelming preference for food obtained through barpressing.

Using the same training schedule, Tarte and Snyder (1973) replicated the results achieved by Carder and Berkowitz (1970). However, when Tarte and Snyder provided equal amounts of counterbalanced training, a clear preference for free food was observed. In his review article, Osborne (1977) suggested that animals seem to prefer barpress food only after they have received asymmetrical training. He defines asymmetrical training as the absence of prechoice training with freely

Requests for reprints should be sent to: George Wolford, Psychology Department, Dartmouth College, Hanover, New Hampshire 03755 . available food and/or unequal pretraining experience with the choice alternatives.

A number of other researchers have examined the effects of training on the choice situation. Jensen (1963) found that the percentage of food obtained via the barpress increased monotonically with increases in the amount of barpress training prior to the preference test. On the basis of their research, McLaughlin, Kleinman, and Vaughn (1973) concluded that the degree of prior barpress training and the choice of response-dependent food in the preference situation may be directly related. Using free food and barpress food in the choice situation, Mitchell and White (1977) compared the effects of equal and unequal training. They demonstrated that rats who have more barpress experience than experience with free food prefer to barpress in a choice setting. Rats who have received equalized training and rats who have received more free-food training prefer free food in the choice situation. Lentz and Cohen (1980) demonstrated that pigeons will respond for food in the presence of free food as a function of the amount of prior keypress training.

Kleinman, McLaughlin, Gerard, Bosza, and Clipper (1976) demonstrated that rats who received barpress training on an FR3 schedule initially prefer this schedule when given the choice between an FR3 and a CRF schedule. They also found that rats trained on CRF schedules and rats trained equally on the two schedules preferred the CRF schedule when choosing between CRF and FR3.

The preference for barpress food following asymmetrical training may not be enduring. Tarte and Rasmussen (1979) trained rats with 3 days of free food and then 6 days of barpress. After housing their rats for a 6-day choice test, they found that rats initially preferred to barpress for food but that this behavior decreased to low levels shortly thereafter. 
Each of the preceding experiments has demonstrated the importance of training on the contrafreeloading phenomenon. In addition to determining that training impacts upon choice behavior, it is important to clarify the extent to which this occurs and the nature of the contribution made by training. In the first experiment, we investigated the limits of training by determining whether preference could be alternated between two choices. In the second experiment, we determined whether this alternation could be continued indefinitely. In addition, we explored whether the rate of food consumption for free versus barpress food might shed some light on the nature of the training effect.

\section{EXPERIMENT 1}

The first experiment was a replication and extension of the experiment reported by Carder and Berkowitz (1970). The purpose of Experiment 1 was to reproduce the barpressing preference and then to test the susceptibility of that preference to subsequent exposure to the two alternatives.

\section{Method}

Subjects and Apparatus. Eight naive male albino rats (Holtzman Co.) approximately 90 days old at the start of the experiment were maintained at $80 \%-85 \%$ body weight and run under 24-h food deprivation.

The apparatus was a one-bar Skinner box (Scientific Prototype) with a standard food magazine. All of the rats received their free food in a glass dish $(6.5 \times 1.5 \mathrm{~cm})$ placed at the rear of the operant chamber.

Procedure. The training procedure was similar to that used by Carder and Berkowitz (1970). The subjects were given 3 days of free-food training during which they consumed 200 Noyes pellets $(45 \mathrm{mg})$. The pellets were available en masse, and the bar was disconnected. Subsequent to all of the training and test sessions, the subjects received sufficient Purina Lab Chow (their standard maintenance food) to maintain an $80 \%-85 \%$ body weight. Two hundred Noyes pellets corresponds to about twothirds of their daily required food. Following the free-food training, the rats received 6 days of barpress training, 200 pellets per day on a CRF schedule, with the free food absent. Immediately following the nine consecutive training sessions, the subjects were given three identical, consecutive test sessions. Each test session began with the subject earning 25 pellets via the barpress. The free food ( 175 pellets) was then inserted into the appropriate location without removing the subject. The subjects were then permitted to earn 175 pellets in whatever fashion they chose. An attempt was made to keep an account of the amount of food consumed while the test session was in progress. This was done with the aid of an electronic counter connected to the bar and by careful visual inspection of the rat's behavior when it was eating from the freely available food. When it was estimated that 100 pellets had been consumed, the rat was removed from the test chamber, and an accurate count was made. Before the free-food container was returned to the chamber, it was filled with an amount equal to 200 minus the actual total number of pellets consumed. The rats were then returned to the operant chamber, and the test session resumed. The estimation procedure was continued during the second half of the session. The counting procedure was sufficiently accurate to ensure a total consumption of $200( \pm 2$ or 3$)$ pellets.

Subsequent to the 3 rd test day, all subjects received 5 days of free-food exposure similar to the free-food pretraining, except that the bar was now shielded with a Plexiglas sheet extending the width of the chamber. The rats were then given a test session identical to the first three sessions. Finally, the rats received 5 more days of barpress training with the free food present, but shielded in Plexiglas, and then were tested. There were, therefore, five test sessions in all.

\section{Results and Discussion}

One subject was discarded due to equipment failure during a test session. The mean percentage of barpress food consumed on each of the choice days was $78 \%$, $89 \%, 95 \%, 4 \%$, and $63 \%$. The standard errors for these conditions averaged $7 \%$. The subjects showed a preference for the barpress food during the first three sessions, and that preference increased during those sessions. Following the posttraining with free food, all of the rats reversed their preferences, eating free food almost exclusively (Test Day 4). Finally, after renewed barpress training, the mean preference shifted back to the barpress (Test Day 5). The preference during that final test session, however, was less marked, and three of the rats ate slightly more of the freely available food than of the barpress food.

Overall there is little doubt that the recent training history had a marked effect on performance. In this experiment, the subjects clearly preferred the alternative to which they had been most recently exposed.

\section{EXPERIMENT 2}

Experiment 1 demonstrated that training could influence strongly a rat's preference for barpressed food versus freely available food. The last reversal (Test Day 5), however, was somewhat weaker than the previous reversals, and the question naturally arose as to whether the preference could be altered relatively indefinitely with posttraining or whether the preference would become fixed at one of the two alternatives. Experiment 2, then, extended Experiment 1 by trying to alternate indefinitely the preference between the barpressed food and the freely available food. In addition, careful measurement of the time required to consume the 200 pellets on both training and test days was kept. It was felt that these times might shed light on the basis of the training effect.

\section{Method}

Four naive rats, meeting the same qualifications as those in Experiment 1, were used. The apparatus was the same as that used in Experiment 1 . All of the rats received their free food in a glass dish placed at the rear of the operant chamber.

All subjects began with 4 days of free-food exposure, followed by 6 days of barpress training and then the first test session. Subsequent to each test session, the subjects received 1 day of rest followed by 4 days of posttraining and a test session. Free-food training was administered prior to the evennumbered test days, and barpress training, prior to the oddnumbered test days. This alternating sequence continued until either the preference remained constant or had been alternated 20 times. Each subject received a water break at the 10-min mark on all training and test sessions. The time required to 
consume the 200 pellets, not counting the water break, was recorded on all training and test days. All other procedural details were identical to those used in Experiment 1.

\section{Results and Discussion}

The mean percentage of barpress food consumed on each of the choice days was $78 \%, 22 \%, 54 \%, 4 \%$, and $9 \%$, respectively. The standard errors averaged $10 \%$. Choice Days 1, 3, and 5 followed barpress training, whereas Choice Days 2 and 4 followed free-food training. These data show that the subjects' preference remained constant on Test Day 5 despite the preceding 4 days of barpress training. Apparently, then, the preference between those two alternatives cannot be manipulated indefinitely through training. After sufficient training, the subjects' preference remained constant at one alternative.

The consumption rates for the various training and test days provide some clues to the observed preference on each test day. Those consumption rates are shown in Figure 1.

There were two particularly interesting points in the consumption-rate data. The first was that considerable improvement occurred over days in the time required to eat free food. The subjects had had no experience in eating small Noyes pellets, and their ability to eat the pellets produced a "learning curve" quite similar to that of the barpress response. Thus, these data suggest that the term "free food" may be an inaccurate description of the continuously available food.

The second point was that, using the rat's last training exposure to each alternative, the results of the test days could be predicted by observing the relative consumption rates of the two alternatives. For ease of comparison, the relative consumption rates at each test day are shown in Table 1. Thus, for instance, on the last exposure to free food prior to the 1st test day (Training Day 4), the subjects averaged 7.8 pellets/min. On Training Day 10 (their last exposure to barpress training before

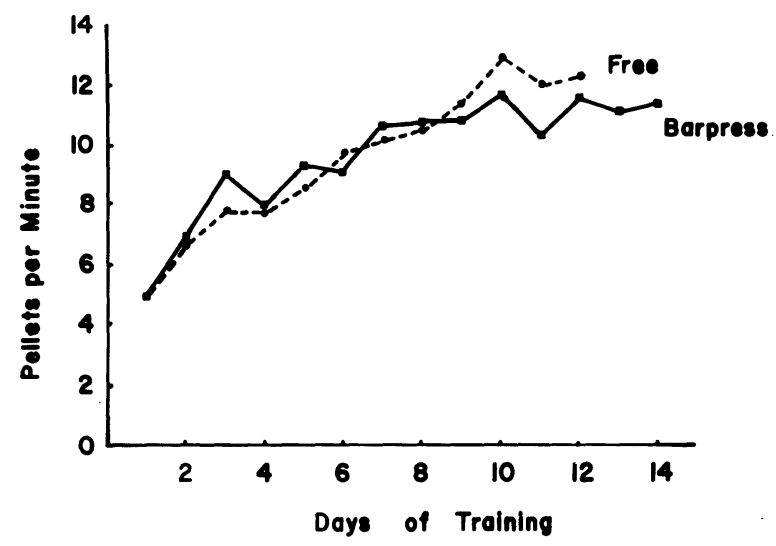

Figure 1. Consumption rates expressed in pellets per minute as a function of training for free food and for barpress food.
Table 1

Relative Consumption Rates (Measured in Pellets per Minute) on the Last Training Exposure to the Two Alternatives Prior to Each Test Day

\begin{tabular}{lrrrrr}
\hline $\begin{array}{c}\text { Most Recent } \\
\text { Consumption }\end{array} \quad$ & \multicolumn{5}{c}{ Test Day } \\
\cline { 2 - 6 } \multicolumn{1}{c}{ Rate } & 1 & 2 & 3 & 4 & \multicolumn{1}{c}{5} \\
\hline Free & 7.8 & 10.5 & 10.5 & 12.2 & 12.2 \\
Barpress & 9.1 & 9.1 & 11.7 & 11.7 & 11.3 \\
\hline
\end{tabular}

the first test), the subjects averaged 9.0 pellets $/ \mathrm{min}$ via the barpress. Given their asymmetric training, barpressing was more efficient than eating from a glass dish on Test Day 1, and, thus, rats preferred to barpress.

The subjects contined to improve on the two alternatives until free food eventually reached a higher asymptote than barpressing. From that point on, the rats preferred the free food. The primary basis of the preference, then, may be the relative rapidity with which the food can be obtained from the two alternatives. The effect of training was to alter the efficiency of the alternative being trained, but continued training had no effect once the asymptotic level of performance had been achieved. It should be noted that it is possible that training influences preference through some mechanism other than consumption rate and that preference, then, determines consumption rate.

\section{GENERAL DISCUSSION}

The outcomes of these experiments confirm previous findings that training plays an influential role in the choice situation. In addition, our research provided some indication of the mechanism through which training operates and some limits on the influence of training. In Experiment 1, preference was alternated between the choices via training. In Experiment 2, it was shown that this alternation did not continue indefinitely. The consumption rates in Experiment 2 indicated that the effect of training is to increase the efficiency of food acquired "freely" or by means of barpressing. When animals receive extensive barpress training, their consumption rates increase, making this alternative method of food acquisition more efficient. The effects of training, however, are limited in that a rat's preference cannot be alternated indefinitely. Rather, the learning curves for each alternative reach their asymptotes after repeated experience. On the basis of Experiment 2, animals ultimately become more efficient at consuming "free food" than barpress food.

The results from Experiment 2 suggest that the preference under study can be predicted from an efficiency or least-effort hypothesis. The least-effort hypothesis, contained in many learning theories (e.g., Hull, 1943; Keller \& Schoenfeld, 1950), suggests that animals have a propensity to maximize reward while minimizing effort. Several researchers have commented on the apparent contradiction between contrafreeloading and the least-effort hypothesis (Kleinman et al., 1976; Larson \& Tarte, 1976; Neuringer, 1970; Osborne, 1977; Singh, 1970). That is, if animals conform to the least-effort hypothesis, then why do they choose to barpress for food when free food is available? Our data show that eating free food is not necessarily more efficient than barpressing. When animals receive asymmetrical barpress training, they are able to consume food pellets more 
quickly by barpressing than by eating from a pile of free-food pellets.

Analogous to our findings, Larson and Tarte (1976) showed that rats can be trained to prefer the longer of two arms in a T-maze if the rats receive asymmetrical training favoring the longer arm. Also Mitchell, Fish, and Calica (1982) demonstrated that rats' preference in a choice situation can be influenced by the relative efficiency with which they can acquire food from the barpress container versus the free-food container.

"Free food" has been defined in the literature as that which is response independent and freely available (Osborne, 1977). That a learning curve results from repeated training exposures indicates that feeding on the so-called "free food" demands a set of responses that become progressively more efficient with repeated exposures. Thus, it is inaccurate to describe a pile of food pellets as response independent or "free."

\section{REFERENCES}

Carder, B., \& Berkowitz, K. Rats' preference for earned in comparison with free food. Science, 1970, 167, 1273-1274.

Hull, C. L. Principles of behavior. New York: Appleton-CenturyCrofts, 1943.

Jensen, G. D. Preference for bar pressing over "freeloading" as a function of number of rewarded presses. Journal of Experimental Psychology, 1963, 65, 451-454.

Keller, F. S., \& Schoenfeld, W. N. Principles of psychology. New York: Appleton, 1950.

Kleinman, K. M., Mclaughlin, R. J., Gerard, I. C., Bosza, D. A., \& Clipper, R. C. Rats' preference for the more effortful of two responses as a function of prior experience. Psychological Reports, 1976, 38, 931-937.
Larson, L. D., \& TARTe, R. D. The effects of training and effortfulness on rats' choice behavior in a modified T-maze. Bulletin of the Psychonomic Society, 1976, 7, 506-508.

Lentz, B. E., \& Cohen, S. L. The effect of prior training on the contrafreeloading phenomenon. Bulletin of the Psychonomic Society, 1980, 15, 48-50.

Mclaughlin, R. J., Kleinman, K. M., \& Vaughn, L. G. Effects of prior training at leverpressing on rats' subsequent responding for food or water in the presence of free rewards. Proceedings of the 81st Annual Convention of the American Psychological Association, 1973, 8, 845-846. (Summary)

Mitchell, D., Fish, R. C., \& Calica, D. R. Rats respond for food in the presence of free food: How free is the "free" food? Learning and Motivation, 1982, 13, 257-263.

Mitchell, P., \& White, K. G. Responding in the presence of free food: Differential exposure to the reinforcement source. Bulletin of the Psychonomic Society, 1977, 10, 121-124.

Neuringer, A. J. Many responses per food reward with free food present. Science, 1970, 169, 503-504.

OsBorne, S. R. The free food (contrafreeloading) phenomenon: A review and analysis. Animal Learning \& Behavior, 1977, 5, 221-235.

Singh, D. Preference for barpressing to obtain reward over freeloading in rats and children. Journal of Comparative and Physiological Psychology, 1970, 73, 320-327.

TARTE, R. D., \& RAsmussen, C. T. Training effects on contrafreeloading in rats housed in operant chambers. Animal Learning \& Behavior, 1979, 7, 69-74.

TARTE, R. D., \& SNyder, R. L. Some sources of variation in the bar pressing versus freeloading phenomenon in rats. Journal of Comparative and Physiological Psychology, 1973, 84, 128-133.

(Manuscript received for publication August 17, 1983.) 